\title{
Innovating Innovation in the U.S. Department of Defense Looking to Large Corporations for Inspiration
}

\author{
John L. Birkler \\ RAND Corporation \\ Paul Bracken \\ Yale University \\ Gordon Lee \\ RAND Corporation
}

\begin{abstract}
In recent years U.S. Department of Defense (DoD) leaders have become increasingly interested in identifying ways to create a culture, policies, and processes throughout the department that yield more innovation than today's environment produces. Many definitions of innovation that the policy community has used, however, have not been clear or intellectually rigorous. Common belief holds that "the bureaucracy" will take charge of the innovation process, with DoD organizing around what are effectively technologies, rather than missions or defeating the enemy. But this paper argues that this approach could hamper U.S. technological performance. The authors propose an alternative innovation framework, one that is policy-oriented, that draws from contemporary commercial practices, and that helps policymakers determine where and when to invest in innovations. In addition, the authors argue that the challenges facing the DoD are closer to those of large companies than to those faced by agile small startups. They conclude by proposing that it is to the DoD examine ways that large companies incorporate AI, IoT and analytics to obtain practical lessons.
\end{abstract}

Keywords: acquisition, defense, agile, agility, innovation, investment, management, mission, organization, process, product, startup, technology

\section{INNOVATING INNOVATION IN THE U.S. DEPARTMENT OF DEFENSE}

In recent years U.S. Department of Defense (DoD) leaders have become increasingly interested in identifying ways to create a culture, policies, and processes throughout the department that yield more innovation than today's environment produces. Innovation has been seen an important way to meet new "peer competitor" security challenges as well as to bring about personnel reductions and get new military capabilities to warfighters faster.

However, many definitions of innovation that the policy community has been using have not been clear or intellectually rigorous. Some have defined innovation in terms of new technology. Others have defined it in terms of staying ahead of other countries in fields like artificial intelligence (AI), big data, and robotics. 
This range of how innovation is defined and understood has resulted in a range of disparate concepts, products, and organizations - all falling under the term "innovation."

This paper argues that DoD must develop a more focused and deliberate innovation approach. The current "portfolio approach" invests in a wide range of technologies. AI, hypersonic missiles, quantum computing, cyberwar, etc. are all supported without an overall architecture of how they would be used with the forces, other than they will replace existing technologies and offer greater performance or efficiency. This approach scatters resources over so many new areas that it loses focus and discipline. In a sense, programs compete against one another rather than toward completing some new tasks or missions.

Common belief holds that "the bureaucracy" will take charge of this process, with DoD organizing around what are effectively technologies, rather than missions or defeating the enemy. But for reasons argued in this paper we feel this will set back U.S. technological performance considerably. It should be emphasized that bureaucracy is a decentralized form of organization. It factors an overall problem into separate, manageable tasks, each of which is assigned to a particular department or group. For this reason and because today's innovation is built on networked technologies, it is more important than ever to drive innovation so that the individual departments coordinate activities across the silos of the organization.

In this paper, we employ a policy-oriented definition and perspective on innovation. This definition is useful whether one is focusing on products, processes, or high-level missions.

We focus on (1) providing a perspective on creating, nurturing, and integrating such new technologies and other innovations within the DoD, and (2) developing a methodology to identify promising areas of investments that benefit the $\mathrm{DoD}$ and which the commercial world is likely to ignore.

Our perspective in this paper differs from a widely made argument that to nurture innovation DoD needs to take more risk, streamline processes, and become more agile. In a nutshell, this view posits that DoD should embrace the types of innovation found in large and small technology companies in Silicon Valley.

In this paper we argue that there are alternative approaches that may offer better prospects to improve DoD's ability to innovate in certain areas. We argue that DoD's highly formalized acquisition system is too risk averse. This aversion to risk and failure is built into DoD's acquisition process and works to impede DoD's ability to fully participate in today's technological revolution.

\section{What Constitutes Innovation in the DoD Setting?}

Innovation is always a matter of degree. It is a continuous spectrum. There are always innovations made up of small changes that improve a product or the workflow in an organization. Software upgrades are example of this. We call these small, incremental changes evolutionary innovations.

There are also more radical innovations that fundamentally change a product or the way an organization works. Amazon has transformed retail in the United States, with far reaching consequences for everything from shopping malls; to ordering, shipping, and delivery; to dynamic pricing. Apple has similarly changed the world with the iPhone ecosystem for personal information and communications.

\section{Evolutionary and Radical Innovation}

For evolutionary innovations, consumers typically know how they are going to use them; what gaps they fill; how many of them they plan to buy; and what those products will cost. Radical innovations don't have these characteristics: their designs are not fixed until late in the adoption process; their impact on the workforce is uncertain; the predictability of their performance and costs, and the size of production runs unknown; and the lengths of their life cycles impossible to know in advance. Table 1 lays out these contrasts. 
TABLE 1

COMPARISON OF EVOLUTIONARY AND INNOVATIVE PRODUCTS

\begin{tabular}{|l|l|l|}
\hline Dimension & Evolutionary & Radical \\
\hline Design & Follow-on & New \\
\hline Technology & Incremental & Disruptive \\
\hline Operational Employment & Established & In formulation \\
\hline Development Outcomes & Predictable & Uncertain \\
\hline Production Run & Large & Uncertain \\
\hline Expected Operational Life & Long & Uncertain \\
\hline
\end{tabular}

Table 1 points out that radical innovations entail far more uncertainties and risks in many more areas than are found in evolutionary innovations. For radical innovations:

- The design is new so that many features of the product or process are not known or are only poorly understood.

- Technology entails integrating subsystems to produce a whole system with unknown interactions among the parts.

- Operational employment and doctrine are not really possible and are subject to substantial uncertainties and change during a learning phase. Often the only way to develop doctrine is to deliver a system to operators and to observe how they use it.

- Production run size and operational life are undetermined (an obvious consequence of the uncertainties surrounding the cost, capabilities, and operational concept of the system).

An example of a radical innovation is the recently developed Sea Hunter unmanned submarine hunter vessel. ${ }^{1}$ It meets all of the criteria listed in the right-hand column of Table 1.

Many radical innovations use existing technologies that are integrated in new ways. Examples of this extend all the way back to the transition of sail-powered naval warships to steam ships of the line. The combination of a reliable steam engine and screw propeller allowed both the power plant and drive train to be placed below the waterline where they were relatively safe from gunfire (Lautenschläger, 1984).

A more recent example of integrating technologies is Uber. Uber integrated three software platform technologies: a GPS based mapping and route-finding system; a payment system of credit cards or PayPal; and a communications system of cell phones to connect drivers with customers. Each of these subsystems existed beforehand. The radical innovation came about from their seamless integration. The effect was radical: disrupting the taxi business model in the United States and across the world. Remarkably, all three systems were interfaced with a single application downloaded to the customer's cell phone. This single app is extremely simple from the customer's point of view. In other words, the effect of the Uber app was to take something that was highly complex, three separate software platforms, and to transform it into a simple tool for the user. Uber is now using this approach to disrupt other industries. They are revolutionizing the restaurant business with a similar delivery model, driving sales to home delivery.

Radical innovation, then, can have far reaching effects. It may take a relatively long period of time to win acceptance, and it is frequently controversial until it is proven in the marketplace for businesses, or in battle for the military (Hundley, 1999).

\section{Scope of Innovation: The Evolutionary-to-Radical Spectrum}

One practical way to think about all of this is that the evolutionary and radical innovations lie on a continuous spectrum. This can be defined as the scope of the innovation. Evolutionary and radical are the two end points.

This framework has useful management implications for DoD. It amounts to deciding where on the spectrum dollars should be invested. The more a marker is laid down toward the spectrum's right-hand side - radical innovation - the greater the uncertainties of cost, schedule, doctrine, and design features are 
accepted. Broadly speaking, for decades after the end of the Cold War the DoD has been operating toward the evolutionary side of the spectrum.

The choice of scope of innovation has many consequences. Consider the case of a business. As a company moves rightward along this spectrum more variables are brought into the problem that have to be addressed. The more radical the innovation the more it brings in non-technological factors that need to be thought through in advance. In a case we discuss in more detail later in this paper, when General Electric attempted to move into predictive analytics, it did not engage in that forethought adequately, with the result that it lost billions of dollars (Financial Times, 2018). ${ }^{2}$ Uber, in contrast, did think through these nontechnological factors when it brought its ride-sharing business to New York, Philadelphia, and Los Angeles and other large U.S. cities. Uber had a large budget set aside and highly trained lawyers to fight the political opposition from taxi fleet owners and government officials who supported them (Abrosimova, 2014).

This scope perspective shows something else that is important. Evolutionary innovation requires only small adjustments to organizational procedures and workflows. For this reason, most managers strongly prefer it over more radical approaches. An important consequence is that if nothing is done to drive an organization to change, usually it won't. The path of least resistance, from an organizational prospective, is evolutionary change.

While evolutionary change may be acceptable in a stable competitive environment, where the organization is performing well, in a world of intense competition and turbulence, performance may well decline. This is because other rivals, or new entrants, have compete on a new basic, with technologies, processes, and strategies.

In this case, pressure is needed to drive change in an incumbent organization, that is, one with a dominant historical position. Since organizations follow momentum paths and stick with evolutionary innovation, unless some pressure or deliberate intervention develops, they will continue on those paths.

How can management be factored into our understanding of innovation? One way is to have another variable that accounts for it, namely the source of change. It's the pressure on an organization to change how it does what it needs to do.

There are really two fundamentally different sources of change in any organization. One is top down pressure. The other source is bottom up. Top down change describes leadership and new ideas that are advanced to solve a problem or improve performance. Bottom up describes innovations that percolate upwards because they are so superior to existing approaches that they are widely embraced.

Physicist Freeman Dyson describes the history of new theories in science in these terms (Dyson, 1999). Top down change comes from truly brilliant scientists, like Isaac Newton or Albert Einstein. They offer new theories for physics which are top down, pulling many particulars together. On the other hand, inventions such as the telescope or the microscope are bottom up changes. They make new discoveries possible because they introduce tools to study the world in a new way. This perspective on innovationoriginating both from top down concepts and from bottom up ones - is found in most fields. Charles Darwin advanced his radical innovation in evolutionary theory. Human paleontology in recent years, in contrast, has seen great advances from the bottom up application of DNA analysis, computerized tomography, and other technologies applied to fossils (Stringer, 2012, describes how new technologies developed in other fields has been applied in recent decades in paleontology).

Which is more important? Freeman Dyson and Chris Stringer are emphatic here. They argue that both sources of new ideas are critical. Without telescopes there could be no understanding of the cosmos-and no theory of relativity. Without DNA technology and tomography, our understanding of human evolution would be far less advanced than it has become.

This perspective applies as well to technology innovation. Top down sources of change for innovation in defense technology may come from several sources. One is leadership. It is leadership that sees changes in the strategic environment and the organization's need to adapt to them. Another source of change could be a new threat. Yet this is the case only if someone at the top recognizes the significance of changes in the environment and takes action to deal with them. ${ }^{3}$

There is no assurance that top down change will work, or that it will always produce the desired result. In fact, that's one of the risks of top down directed innovation. As we discuss in detail later in this paper, 
General Electric's (GE's) move into the field of predictive analytics involved top down changes. But in directing changes from the top GE missed multiple important factors. It did not, for example, retrain salespeople to explain the change to customers. Nor did it change its reward system or its enterprise's organizational structure.

Top down innovations require a great deal of planning, clear goals, and transparent performance standards. Think of the Manhattan Project, or the development of the U.S. intercontinental ballistic missile (ICBM) program in the 1950s and 1960s. Both were top down and directed by the leadership.

Some innovations, however, should originate lower in the organization. They are closer to the real work that has to be done. Because of this they can better analyze whether an innovation is really needed, and how it should be implemented. This is bottom up innovation. Unlike top down innovation, bottom up innovations may not require a great deal of buy in for support. They can be introduced piecemeal, in different parts of the organization at different times. ${ }^{4}$

Bottom up innovations come without the top-down approach's baggage. They may be piecemeal and look different across service lines. The NSA was the first DoD element to notice the importance of the shift to digital communications in the late 1990s. ${ }^{5}$ It made larger investments in these technologies than the military services. In many respects NSA's innovations in cyber espionage and cyber war in the early 2000s served as models for the services years later. That is, they constituted an innovation platform. This uneven pattern is typical of bottom up innovation.

It should be clear that the top down/bottom up source of change is also a continuum. Rarely is an innovation purely one or the other. In defense, the Manhattan Project probably comes closest to a pure top down innovation, as it was developed by scientists with presidential backing. But Manhattan-like projects are extremely rare.

\section{Types of Change Created by Innovation}

Combining the two variables of scope and sources of change for innovation allows us to identify different typologies of innovation. Figure 1 combines the two factors discussed above and shows the types of change associated with the different combinations.

FIGURE 1

TYPES OF CHANGE BASED ON SCOPE AND SOURCE OF INNOVATION

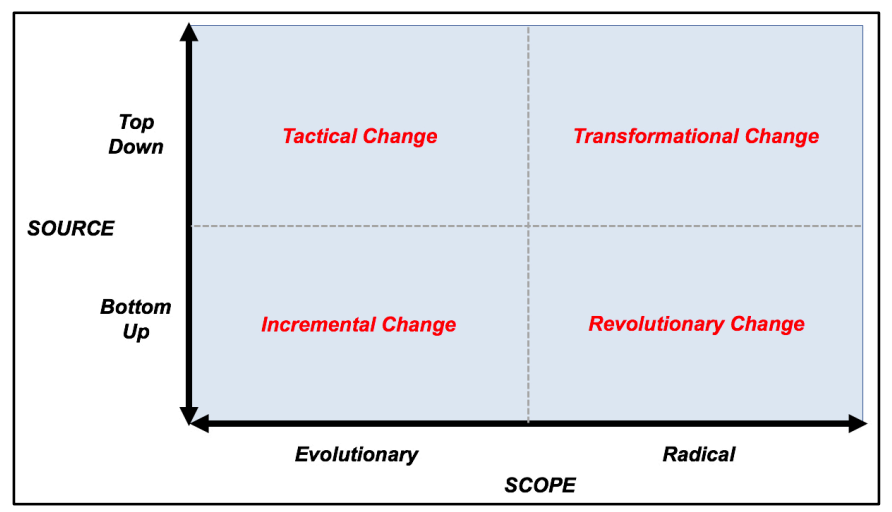

A key point conveyed by Figure 1 is something that also is a lesson both from large corporations and Pentagon-led innovation effort: leaders need to anticipate how the scope and source spectrums will dictate the nature of change. The two cannot be looked upon separately, as independent of one another. ${ }^{6}$ In particular, radical innovation in, say, technology requires changes that address an organization's strategy, processes and structure.

The upper left box in Figure 1 describes changes that are top down and evolutionary. This can be called tactical change. Tactical change is intended to address a single problem. It requires adjustments in factors 
(rewards, people, structure, performance markers) but which can largely be confined to one part of an organization. A good example of this is Uber. Uber started in the ride business. Now it "sells" other products, like food delivery from restaurants (Uber Eats). Uber added this new line only after working out its ride service. The differences between delivering people - and meals - are certainly real. But they are not that different.

The lower left box deals with changes that are evolutionary and bottom up. We call this incremental change. In many ways it describes DoD in the 1990s. Changes occurred, but they were usually driven by improvements from within the Army, Navy, and Air Force. Aircraft performance improved, missiles became more accurate, and warships gradually increased their ability for shore bombardment. Broadly speaking, DoD leadership tended to stay out of the way. These were highly complex changes requiring enormous insider knowledge of the targeting process. They were better left to the individual services. DoD did assist this, however. It created regulatory-bureaucratic paths to fast track certain innovations that looked especially promising. An example of this was Advanced Concepts Technology Developments (ACTD) program.

The upper right box in Figure 1 describes changes that are top down and radical. We call these transformational changes. There are several DoD examples of these, but unfortunately many of them did not succeed. The effort by Secretary of Defense Robert McNamara to restructure DoD for counterinsurgency war in Vietnam, and Secretary Donald Rumsfeld's attempt to transform the Pentagon to make it more quick reacting and agile in the early 2000s are examples. By most accounts these changes never really took hold, and worse, they created problems such as over-centralized decision making, and increased conflict between Office of the Secretary of Defense and the services. ${ }^{7}$

Revolutionary change, as depicted in the lower right quadrant of Figure 1, entails changes that are bottom up and promise radically improved performance. This is an especially important category now because we believe that it describes today's advanced technologies and DoD. The complexity introduced by the addition of AI, data analytics, cyber, unmanned systems machine learning, 5G, etc., are such that top down direction is for all practical purposes impossible. No one person or group understands all of these technologies, yet alone their strategic applications. More important, no one can anticipate the impact of these technologies on people, structures, processes, and management. Therefore, the only way to get something done is to rely on bottom up approaches. This means allowing the services and the Commands to go on their own. DoD leadership - once again — can supply resources and remove bureaucratic obstacles. It can try to connect outside innovation centers in Silicon Valley, Boston, Austin, and elsewhere to the services and Commands. ${ }^{8}$

The real story of Figure 1 isn't negative, however. It's that the chance of successful innovation-driven changes may be improved by careful assessment of the variables shaping the technology and organization carrying it out. Success stories, and failures, can be found in every quadrant of the figure. The greatest failings occur when there is no assessment, that is, when models of innovation presented by the media, uninformed commentators, and leaders with many other demands on their time, are accepted as "the" best way for innovation strategy. We believe there is a strong tendency in this direction in DoD today, described by the portfolio approach of investing a little bit in a wide range of unrelated programs.

\section{What Are the Outcomes of Innovation Changes?}

Previous RAND research suggests that the innovation environment is complex and produces three different types of innovation outcomes: product outcomes, process outcomes, and mission outcomes. Such outcomes are the "output" of the innovation effort, i.e., an improved product or process.

\section{Product Outcomes}

Product outcomes are often the first things that catch peoples' eyes. For historical reasons most of the DoD acquisition system is built to manage product innovation. The products - tanks, ships, aircraft, missiles - are discrete units.

Examples of product outcomes include precision guided munitions, cruise missiles, and drones. Once products are deployed and performance improves, people begin to see better ways to use them. Frequently, 
after mastery of the product technology is completed the emphasis in innovation shifts to process outcomes - a new design of the flows of work and information in the organization that the new technology is embedded in.

\section{Process Outcomes}

Alternatively, there might be a transformational effort to streamline the processes of an organization. This would constitute a top down effort to make the institution more efficient and agile. Many companies and enterprises are attempting to do this today. A process can be defined as "a flow of work or information." Processes have always been important. Napoleon developed a unique communications system to direct his disparate multinational corps, which were dispersed over a large geographic area. In World War II the hunt for German submarines was built around process changes. It required extensive integration of information flows to locate German submarines. Signal intercepts, visual sightings, port watchers, decryption and translation of messages - all had to be coordinated in a timely manner for the mission to succeed.

Processes today have gone far beyond the levels of even the Cold War. Tracking enemy mobile missiles, to take one example, involves integration of multidomain sensors (pictures, intercepts, hacks, drone cameras). The collectors of these data have to be coordinated. Drones need to be launched to the right locations. Cyber penetrations need to be initiated. Weapons need to be linked to this data flow. Moreover, because the data involved in this operation are so diverse, voluminous, and collected in real time, military leaders need AI, data analytics, and cloud computing to manage it all.

In recent years process outcomes have been a major focus in private industry. Walmart, Amazon, and Starbucks naturally try to innovate with new products. But the revolution that these firms have led to is just as much related to process innovation. Take a simple example of Starbucks. Its original valued-added product derived from coffee as a beverage. But over the last few years, the company introduced an app that allows customers to order coffee and food for pickup. This has led to large new sales from its existing stores and the brewing machines in them. That is to say, the value of the stores and machines has grown from innovation in the ordering process, without any new, large capital expenditure.

Another example: The Walt Disney Company has made significant efforts to manage queues at its theme parks. These innovations - RFI chips in bracelets, scheduled time for rides, "platinum" service that allows customers to go to the front of the queues - are top down, but relatively small. Such a process outcome is a good example of what tactical changes discussed above can produce.

Another reason for process innovation is the increasing cost of services. An example is self-checkout at Walmart and supermarkets. Customers don't like long checkout lines. But it's very expensive to hire checkout personnel because of increases in the minimum wage, employment taxes, workers compensation payouts, etc. The cost of the service - checkout - has grown enormously in the past decade. So Walmart and supermarkets have installed self-checkout kiosks. The lines are shorter, work is shifted to the customer, and the kiosks don't take coffee breaks. This all translates into more sales per employee for Walmart. It also leads to lower employee headcount — another cost reduction. ${ }^{9}$

Innovation-driven process outcomes are becoming extremely important for DoD. Almost 30 percent of the department's total civilian workforce in 2017 became eligible to retire by the end of 2022, according to DoD human resource data. ${ }^{10}$ If a significant number of those employees choose to exit government service in that period, the department will be challenged to fill the vacancies. If instead it chooses to "do more with less," it will need to quickly adopt and put in place a range of process innovations. ${ }^{11}$

\section{Mission Outcomes}

Mission outcomes, the third type of innovation outcome, go beyond products and processes. They entail innovation-driven outcomes in operations and tasks that allow entirely new missions. This is called "business model" innovation in industry.

A good example is Amazon. Amazon can't be understood if analyzed only as a case of product and process innovation. It has both of these, certainly. But its more fundamental innovation outcome was its creation of a new business model that sells goods over the Internet without a brick and mortar store presence. 
In defense, examples of mission innovations include ways to counter insurgents in Afghanistan and Iraq and countering anti-access strategies in the Pacific. Counterinsurgency is hardly a new mission for the United States. But the way it was conducted in Iraq constituted a new approach to the mission, employing very accurate weapons, skilled use of intelligence, and thorough reconnaissance of the enemy (Godfroy, 2019). This approach required far fewer U.S. troops to be in direct contact with the insurgents than was the case in Vietnam and other insurgencies. The result: fewer U.S. casualties.

DoD's approach to innovation is still largely centered on hardware and technology, i.e., on new products. But process and mission outcomes will be critical for the department to achieve its goals. Weapon and command and control systems are becoming increasingly complex, and outcomes that get the components of these systems to work together are likely to see greater pay offs than improvements in individual systems. At the same time, the department is spending 50 percent of its budget on services, ${ }^{12}$ an historically high level of spending that could benefit greatly from of innovation-driven process and mission improvements.

\section{How Can DoD Identify the New Technologies and Processes to Support?}

The U.S. Navy sought RAND's help a few years ago in determining which of its laboratories it should keep and which it should close (Saunders, et, al., 1995). The Navy was interested in identifying laboratories that were working on its most innovative and highest-priority technologies. RAND used two criteria for evaluating the laboratories' research and technology capabilities and areas of focus. The first was the relative future value of a laboratory's ability to produce innovative research or technologies that uniquely advance Navy capabilities. The second criterion was breadth of the market for the laboratory's products and innovations. That market extended from Navy-unique customers or uses, through DoD- or government-only customers to broad customer bases beyond the government (see Figure 2).

The Navy used a variant of this chart to justify investing in select labs that concentrated on innovations and products specific to the Navy's needs, which operated in the space depicted in the green-colored portion of the graph; to cease investing in labs that were not operating in that space; and to reorganize others so that they could operate in that space.

This framework offers a way to (1) spot promising commercial technologies that offer innovative, new, unique, or game-changing military capabilities and (2) avoid investing in capabilities and technologies that the commercial world likely will develop. While this analysis was done for the U.S. Navy, the same methodology could be pursued in other contexts or for new technology development proposals.

FIGURE 2

FRAMEWORK TO MEASURE MARKET BREADTH AND RESEARCH VALUE

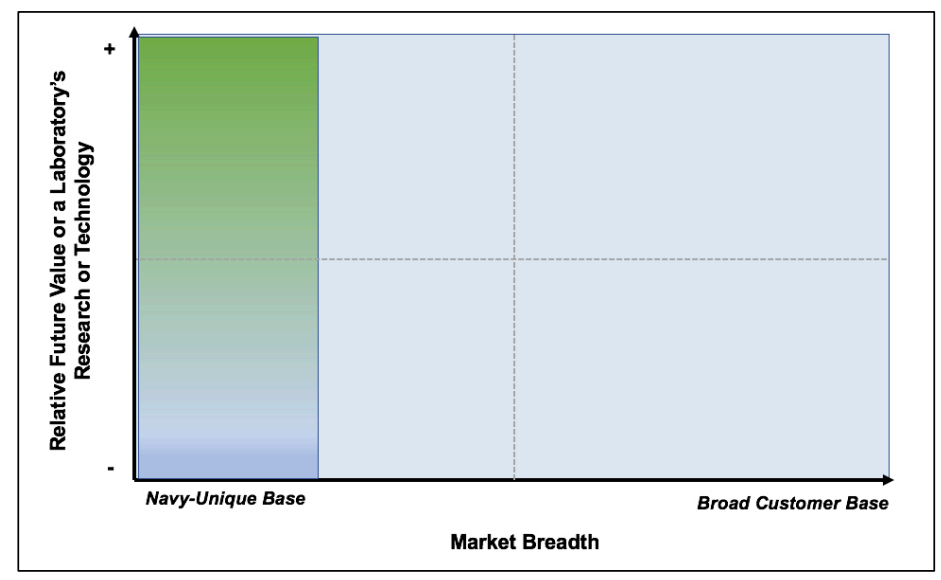




\section{When in the Life Cycle of a Technology Do Investments Provide the Most Leverage?}

Advances in technology often follow an S-shaped curve. The curves are useful because they show the maximum value a given technology can achieve as an asymptote. For example, turbine inlet temperature is what most determines the performance of a jet engine. The higher the temperature, the better the performance. There reaches a point when all the oxygen is burned, and that is the maximum temperature achievable - the asymptotic value. ${ }^{13}$ Beyond that, better performance requires an altogether different technology.

Another example of an S-shaped curve is Figure 3, which displays the increase in efficiency of two different types of lights. For both the incandescent and fluorescent lamps, the first models showed a low level of efficiency, which underwent a rapid improvement, followed by a leveling off as the ultimateasymptotic value - for that technology (graph redrawn from Martino, 1972). Note that in order to be competitive, the initial models of fluorescent lamps had to be almost as good as the latter models of the incandescent lamp. The chart could be updated to show the emerging LED curve, which occurred just as the fluorescent lamps reached their maximum efficiency (Martino, 1993). ${ }^{14}$

These curves capture the fact that when a technical approach is new, growth is slow owing to initial difficulties. It takes time to assure users of the technical and economic advantages over existing systems. Once these obstacles are overcome, performance growth improves more rapidly. As a physical limit is approached, additional improvements become harder, and growth again slows with marginal returns to investment.

The advantage of these types of curves for a given technology is that they show when an investment can provide maximum leverage. For example, investing close to the asymptotic value would not provide as much leverage as an investment early on.

\section{FIGURE 3}

\section{INCREASE IN EFFICIENCY OF MERCURY VAPOR/FLUORESCENT LAMPS AND INCANDESCENT LAMPS}

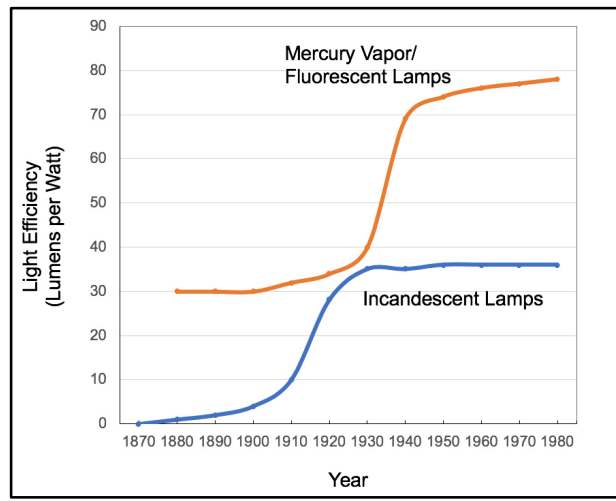

The S-curve pattern describing product innovation is related to another useful concept for characterizing more complex innovations such as AI and machine learning. A dominant design is a technology management concept used to describe key technological features that become de facto standards. These key features may frequently be characterized as following an S-shaped improvement pattern. Features come to define a dominant design when their basic character is selected to be a standard for the entire system. ${ }^{15}$

Dominant designs are useful because they describe innovations in more complex systems with multiple elements and constraints. The shift from propellers to jets, for example, entailed many additional technological changes. These included surface controls, cockpit systems, and metallurgy.

Innovative early technologies generally do not have a dominant design. That is, there is wide disagreement about what the dominant design should be, and so rivals each come up with their own favorite. 
The different early designs fight it out in the marketplace to determine which will predominate. Think Betamax versus VHS. Likewise, it wasn't clear that HTML would become the dominant design for internet programming in the 1980s. There were many other competing software products. But over time HTML became the de facto standard for programming on the web. Nor is there any guarantee that HTML will remain the dominant standard. Just as there is no guarantee that swept wing jets will remain a dominant design. Unmanned vehicles, aerodynamically unstable aircraft, and others are all possible superior dominant designs (Lee, 2018). ${ }^{16}$

It is not hard to see how the ideas discussed here-market breadth, S-shaped curves, dominant designs - are of practical use for DoD leaders. They all get "above the technology" so to speak. They look at innovation from the perspective not of a specific technology, because the best technology may have little military value. Rather, these frameworks and concepts offer a way to allocate resources to the most valuable contributions to overall DoD missions.

\section{Defining Small Startup and Large Enterprise Innovation Models: Which Is Appropriate for DoD?}

DoD's current innovation focus appears to concentrate on the behavior of small- to medium-sized startups, which some observers assume refers generically to companies that have arisen in California's Silicon Valley region or similar venture capital-backed businesses in Austin, Durham, and Boston. Many of these companies' names may be unrecognizable because they have limited scale and spend little on marketing. Their names are generally not recognized because they have not attracted many real customers yet. $^{17}$

But innovations also arise from another source: large enterprises with demanding customers and processes and procedures that must be followed for legal and regulatory reasons. Here, think Apple, Google, Facebook, IBM, GE, Accenture, W.L. Gore, Wells Fargo, and PepsiCo. This group includes Kodak, Blockbuster, and Polaroid because the innovation world contains mega failures. These sources of innovation oversee complex tasks or multi-technology combinations that are much closer to those that America's military services face in building more connected sets of platforms, sensors, and networks.

The two kinds of organizations - small and large - have fundamentally different characteristics. The former is all about small agile startups trying to build markets for new technologies. Failure is tolerated, agility is necessary, and rules and regulations are tossed out the window. Small startups often operate in a munificent environment. Funding for this type of company has veritably exploded in recent years with private equity and venture capital as accepted asset classes that endowments, pensions funds, and others invest in. Moreover, startups that overspend on product development can seek another round of venture investment. This is one of the great strengths of Silicon Valley and its financial backers. Many supporting institutions exist to make this happen.

The innovation environment encountered by large enterprises is vastly different from that faced by small startups. Consider the myriad of regulations that have to be followed by large, multinational corporations. Companies with shares that are publicly traded face an array of accounting rules that are barely a consideration for small startups. Here, if a large enterprise overspends on new product development, or if its scaling costs overshoot estimates because it cannot hire enough of the right kind of engineers, it is in serious trouble. Project delays are likely to be severely punished — not rewarded — by the stock market, analysts, and rivals.

General Electric (GE) is an instructive example of the small-company, large-company difference. It badly managed its digital transformation following a century-long string of successful adaptations to a changing business environment, and its failure in just one strategic innovation-its move into predictive analytics and software - nearly dragged down the entire company (Financial Times, 2018) ${ }^{18}$ GE initiated this in 2012 for several of its strategic business units, including aircraft engines, power generators, and health care capital equipment. But by 2017 revenues from these new business models were not meeting forecasts. A downturn in power generation compounded GE's financial challenges and forced it to abandon its foray into data analytics. 
The point of this GE example is that the firm tried to change too many things all at once: customers, markets, personnel, reward systems, and technology. GE is an example with significant relevance for DoD: that there are big risks to trying to change too much all at once.

\section{CONCLUSIONS}

The big story in business today is that large companies are aggressively moving into the new technologies of AI, data analytics, and machine learning. They have concluded that such moves are essential if they are to stay in business. They see the risks and are still investing in the technologies because they see no way of surviving if they do not. How they-as large, complex enterprises much like the military services - proceed in this endeavor is of great relevance to DoD.

The differences between the small startup environment and the large company environment can be seen by returning to Figure 1 and Figure 2. In both figures, small startups tend to focus on subsets of large companies' areas of concern. Small startups gravitate toward the right side of each graph, paying particular attention to radical innovations in Figure 1 and to the broader customer base in Figure 2. Large firms tend to spread their innovation efforts across all four quadrants in both figures.

Regardless of the quadrant where they occur, advances in technology often follow an S-shaped curve that show different rates of growth; when a technical approach is new, growth is slow owing to initial difficulties. Once these obstacles are overcome, growth rapidly improves. But as physical limits are approached, additional improvements become harder, and growth again slows. The advantage of these types of curves for a given technology is that they show when an investment can provide maximum leverage.

Figures 1 and 2 show that small startups may not always be a useful model for something as large and complex as DoD. While small startups may be helpful in prototyping or in introducing radical new technologies-AI, machine learning, cyber - the model fails to account for what GE and other organizations have learned the hard way. The innovations may not lead to the intended effects because they overlook the other organizational elements. Small startups do not always have to worry about these elements, because they do not operate in a world where these factors of implementation must be considered.

But DoD isn't like this. If it does not have the right systems and the right communications in place, the enterprise's performance will suffer a drastic decline. ${ }^{19}$

There are two big lessons to be drawn from this discussion of innovation models and their salience for DoD.

- Small startups offer useful examples of innovation, but they constitute only one model. A much more relevant innovation model for DoD comes from large corporations' digital transformation and strategic innovation initiatives. Large enterprises have to pay attention to incremental and tactical changes as much as they do to revolutionary and transformational changes.

- There are numerous case studies and potential examples that may offer the DoD insights into what does and does not work. With respect to digital transformation and adaption of the new technologies, for example, IBM, GE, Google, Accenture, Wells Fargo, and PepsiCo are all trying to incorporate $\mathrm{AI}$ and machine learning to their operations.

We strongly believe that the challenges facing the DoD are closer to those of large companies than to those faced by agile small startups. It is to DoD's advantage to explore a different world of innovationhow large companies incorporate AI, IoT and analytics - to obtain practical lessons.

\section{ENDNOTES}

1. The Sea Hunter is an autonomous unmanned surface vehicle launched in 2016 as part of the DARPA AntiSubmarine Warfare Continuous Trail Unmanned Vessel program. It was christened on April 7, 2016, in Portland, Oregon and was built by Vigor Industrial.

2. This discussion also draws on Paul Bracken's analysis of the GE case for his course on Technology and Global Strategy, MGT 888, at the Yale School of Management. 
3. In national security there are many examples of this. Winston Churchill saw the clear danger in Hitler's rise, and he orchestrated and accelerated many technology initiatives. Recently, Kim Jong-Il accelerated a top down program for accelerated missile and atomic bomb development in North Korea, shaking up what was a slow-moving program.

4. Innovations leading to the cruise missiles in the U.S. military are a good example of this. The Army originally saw cruise missiles as a new kind of long-range artillery. The Air Force saw them in terms of nuclear strike, and later as instruments for precision conventional strike and as a way to reduce collateral damage. The Navy after the Cold War saw cruise missiles as a way to boost firepower to hit shore targets "from the sea." All of these roles are different, and the best way to meet the different demands was allowing each service to innovate in its own way. The role of the top leadership in DoD was to provide resources to the services, remove bureaucratic impediments - and get out of the way of the services.

5. The NSA innovations of the early 2000s were observed by one of the authors (Bracken) serving on various government advisory panels and working with intelligence related private equity firms.

6. Moreover, the two spectrums cannot be ignored. Doing so increases the risk that desired changes will not come about. It also would increase the risk of significant internal conflicts in the organization.

7. This is what studies refer to when they say that two-thirds of all transformation efforts fail. However, there are some success stories in the business world of transformational change. Boeing's 787 Dreamliner was a radical departure from all previous aircraft in that it bypassed the building and testing of a prototype. Instead, Boeing used top down directed IT connected suppliers to integrate the plane from the individual parts. But even here, Boeing ran into problems. The 787 was ultimately a highly successful product, with great fuel efficiency and other improvements. But it took years of delay from rework to actually get the 787 into the world's air carrier fleets.

8. Readers need to bear in mind that the changes and variables described here are not pure, absolute types but rather fall along a continuum. This description of the different kinds of innovation-driven change is useful because it helps to put some boundaries around an otherwise anomalous subject of complex technology and ways to lead and manage it for useful strategic purposes. The framework also shows why no set of acquisition regulations could possibly tame the disruptive technologies that $\mathrm{DoD}$ is now developing. Simply put, there are no written policies and procedures that could enforce compliance to the kind of rule set that has governed defense acquisitions for decades.

9. Other examples of this include boarding pass kiosks at airports, self-service checkout at public libraries, and self-ticketing in municipal subway systems.

10. GAO analysis of the Office of Personnel Management's Enterprise Human Resources Integration database, p. 1. As of September 30, 2017: www.gao.gov

11. Indeed, the DoD's acquisition process may be ripe for innovation. As defined in DoD's 5000 series of directives, the process is simply not congenial to programs that involve a range of important uncertainties. One key problem lies in the acquisition process' sequence of decisions and actions and in the process' ability to tolerate uncertainty. Early on, when defense leaders are trying to decide how to fill a capability gap, the DoD performs a series of studies that are followed by a Milestone A decision, at which point a system is clearly defined, and in effect, locked in. Then the sponsor commits to fund its development and initial production. In the case of highly innovative systems, major uncertainties and risks are not likely to be resolved adequately by this milestone. Thus, the acquisition process - which is not geared to accommodate significant cost, schedule, or performance uncertainties-eliminates these systems from further consideration. The result: innovation is stifled.

12. Interview with then-Deputy Secretary of Defense Ash Carter, Defense News, November 19, 2013.

13. Examples of asymptotic values that set a limit to the performance of a technical approach include absolute zero, compressive strength, efficiency limits (always 100 percent), speed of light, and speed of sound.

14. See Martino, 1993: "The history of a technology will often show a sequence of different technical approaches. Each new approach usually represented a breakthrough, since it surpassed the upper limit of the previous approach. Thus, a plot of the performance of individual devices in the history of the technology might show a succession of growth curves, one for each technical approach."

15. An example will show the concept of dominant design. All aircraft were originally biplanes. Over time the constraints of this design were gradually understood. The biplane gave way to a new design. This was the 
enclosed cockpit propeller driven airplane. After that, swept jets were developed. The three dominant designs - biplane, fixed wing propeller, swept wing jet — were each the dominant designs of their era.

16. One of the major questions in AI, for example, is whether a dominant design will emerge. Early AI efforts were based on symbolic manipulation of rule-based systems. These were called experts systems and they became a dominant design in AI. But more recently neural networks have become a dominant design. This design uses hidden Markov models and very large amounts of data for the AI to "train" the algorithms (see Lee, 2018).

17. Small firm investment opportunities are overseen in DoD by groups such as DIU (Defense Innovation Unit) and the SCO (the Strategic Capabilities Office), which concentrate on bringing in new contractors and encouraging new ideas. In essence, DIU and SCO change how concepts, technology, and perspectives flow into the DoD's acquisition system.

18. See Financial Times, February 26, 2018. This discussion also draws on Paul Bracken's analysis of the GE case for his course on Technology and Global Strategy, MGT 888, at the Yale School of Management.

19. It is actually worse than this for DoD because it also needs to respond to national leaders with assurance. If it is assigned a mission, it must be confident that it will succeed. DoD needs to give assurances to the political leadership about the risks and downsides of operations.

\section{REFERENCES}

Abrosimova, K. (2014, May 22). Building an app like uber: What is the uber app made from? Yalantis Product Development.

Dyson, F.J. (1999). The sun, the genome, and the internet, tools of scientific revolution. Oxford University Press.

Financial Times. (2018, February 26). Learning the lessons of GE's steepening decline.

Godfroy, J., Zais, M., Rayburn, J.D., Sobchak, F., Powell, J., \& Morton, M. (2019). The U.S. Army in the Iraq war volume 2: Surge and withdrawal 2007-2011. United States Army War College Press.

Hundley, R.O. (1999). Past revolutions, future transformations: What can the history of revolutions in military affairs tell us about transforming the U.S. Military? RAND Corporation.

Lautenschläger, K. (1984). Technology and the evolution of naval warfare 1851-2001. National Academy Press.

Lee, K. (2018). AI superpowers, China, Silicon Valley, and the new world order (pp. 8-9). Houghton Mifflin Harcourt.

Martino, J. (1972). Technological forecasting for decisionmaking. American Elsevier Publishing.

Martino, J. (1993). Technological forecasting for decisionmaking. McGraw-Hill.

Saunders, K., Augenstein, B., Bracken, P., Krumel, G., Birkler, J., Chiesa, J., . . Nichiporuk, B. (1995). Priority-setting and strategic sourcing in the naval research, development, and technology infrastructure. RAND Corporation.

Stringer, C. (2012). Lone survivors, how we came to be the only humans on earth. Times Books. 